Research Trainee

\title{
Intimate Partner Violence Against Indigenous Men in Heterosexual Relationships: Toward a Culturally Safe Response in Primary Health Care Settings
}

\author{
Kristin Rizkalla, Marion Maar, Maurianne Reade, Roger Pilon, Lorrilee McGregor
}

\author{
A R T I C L E I N F O
}

Keywords:

Northern Ontario

Indigenous men

First Nations

Intimate partner violence

Primary care providers

Cultural safety

https://doi.org/10.32799/ijih.v16i1.33060

\begin{abstract}
A B S T R A C T
Most Indigenous intimate partner violence (IPV) research and interventions are geared toward women, while the experiences of Indigenous men as survivors of IPV are not well investigated or understood. Indigenous men are typically portrayed as perpetrators of violence yet very seldom as survivors of violence, although they experience disproportionately high rates of violence, including IPV, when compared to non-Indigenous men. Our community-based participatory research, conducted in partnership with First Nations communities in Northern Ontario, Canada, completed in 2019, identified this bias as a major barrier for Indigenous men to disclose IPV in a health service setting, where a safe space and support should be available. The primary health care providers involved in this study reported awareness of serious abuse perpetrated against First Nations men in heterosexual relationships. However, they also cited insufficient preparedness within the primary care system to respond to the needs of these men, including significant gaps in culturally safe services. These findings warrant attention and action. We offer recommendations for health and social services and community organizations to help address, in culturally safe ways, IPV experienced by Indigenous men and its effects on families and communities.
\end{abstract}

Kristin Rizkalla, MSc, Department of Interdisciplinary Health, School of Rural and Northern Health, Laurentian University, Sudbury, Ontario, Canada. Primary author, currently PsyD candidate in clinical psychology.

Marion Maar, PhD, Associate Professor and Founding Faculty, Northern Ontario School of Medicine, Laurentian University Campus, Sudbury, Ontario, Canada. Corresponding author, primary supervisor, and senior researcher who guided the development of the study in collaboration with participating communities. Email: mmaar@nosm.ca

Maurianne Reade, MD, CCFP (EM), FCFP, Associate Professor, Division of Clinical Sciences, Northern Ontario School of Medicine. Shared co-researcher expertise as a long-standing primary care provider in participating First Nations and rural communities.

Roger Pilon, PhD, NP-PHC, Director/Associate Professor, School of Nursing, Laurentian University; Assistant Professor, Division of Clinical Sciences, Northern Ontario School of Medicine. Shared co-researcher expertise as a long-standing primary care provider in First Nations communities.

Lorrilee McGregor, PhD, Assistant Professor, Division of Human Sciences, Northern Ontario School of Medicine. Shared coresearcher expertise in community-based research in Indigenous communities and member of one of the participating communities. 


\section{Acknowledgements}

We would like to thank the 31 participants who were involved in this study and who shared their experiences with interest and compassion. We would also like to thank the participating First Nations communities and affiliate organizations. In addition, we are grateful to the Women's College Hospital's Women's Xchange \$15K Challenge and Canadian Institutes of Health Research for the funding to carry out this project.

\section{Introduction}

You can't address intimate partner violence without looking at both sides of the equation - what's occurring in relationships. (Participant)

Intimate partner violence (IPV) is any behaviour in an intimate relationship causing physical, emotional, sexual, psychological, financial, or spiritual harm (Centers for Disease Control and Prevention, 2018; World Health Organization, 2012). In Canada, IPV experienced by men in heterosexual relationships is generally not well investigated or understood, or a focus for health and social services (Brownridge, 2010). In contrast, the experiences of women are increasingly well documented, including the magnitude of the problem affecting Indigenous ${ }^{1}$ women (Brownridge, 2003; Klingspohn, 2018).

Mainstream studies suggest that women sustain more severe injuries from IPV perpetrated by men than vice versa; however, the physical, psychological, and financial consequences of women-perpetrated IPV toward men are neither rare nor insignificant (Desmarais et al., 2012b). In fact, several studies have suggested that men and women experience IPV in similar proportions when severity of injury is not taken into account (Desmarais et al., 2012b; Fiebert, 2014). For example, Desmarais and colleagues (2012a, 2012b) reported pooled estimates of IPV between women and men across 10 years and found that 1 in 4 women $(23.1 \%)$ and 1 in 5 men (19.3\%) have experienced physical violence in an intimate relationship. Criminal data yield small numbers of female-perpetrated IPV, but men may underreport violence against them to police due to stigma, or because they may be generally less fearful or injured when harmed. In addition, there are barriers such as gender bias that make it difficult for men to address IPV through the criminal justice system (Desmarais et al., 2012b).

\section{IPV Perpetrated Against Indigenous Women}

The elevated rates of violence against Indigenous women, including IPV, must be understood through the lens of colonialism and intergenerational trauma. Research shows that much violence against Indigenous women has been caused by colonial policies and structures such as the Indian Act, the Sixties Scoop, and the residential school system which have all put women in harm's way for generations. Indigenous women have been subjected to systemic racism and patriarchal structures that have enabled high rates of human rights violations as well

\footnotetext{
${ }^{1}$ Unless stated as "First Nations," the term "Indigenous" is an all-encompassing term which can refer to persons who identify as First Nations (Status or Non-Status), Métis, or Inuit (Bartlett et al., 2007).
} 
as physical, mental, spiritual, and sexual abuses. As a consequence, the strong roles that Indigenous women typically held in traditional cultures have been violated and eroded (Innes, 2015; Innes \& Anderson, 2015; National Inquiry into Missing and Murdered Indigenous Women and Girls, 2019).

The estimates of the prevalence of IPV experienced by Indigenous women vary widely in the literature. This can be attributed to factors such as underreporting, study methodology, how IPV is defined, and location and history of communities studied (Andersson \& Nahwegahbow, 2010; Brownridge, 2003). While estimated rates vary between 25\% and 100\% (Brownridge, 2003), researchers agree unanimously that Indigenous women face disproportionately higher rates of IPV compared to non-Indigenous women in Canada (Andersson \& Nahwegahbow, 2010; Benoit et al., 2015; Romans et al., 2007). Studies suggest that Indigenous women are 8 times more likely than other women in Canada to experience abuse by their partners (Andersson \& Nahwegahbow, 2010; Ontario Native Women's Association, 1989) and are 5 times more likely to die from violence (Amnesty International, 2004; Indigenous and Northern Affairs Canada, 2001).

\section{IPV Perpetrated Against Indigenous Men}

Violence perpetrated against Indigenous men should also be examined in the context of colonization because its consequences of the latter include systemic racism, police brutality, harsher sentences in the criminal justice system, and high in-custody death rates (Innes \& Anderson, 2015; Hansen \& Dim, 2019; Mt. Pleasant, 2016). Mt. Pleasant (2016) states that, in general, "Indigenous males have largely been studied from the perspective of the perpetrators of violence" (p. 3), but victimization of Indigenous men has been largely ignored. Emerging research shows that Indigenous men experience higher rates of violence, disappearance, and murder compared to both non-Indigenous men and Indigenous women (Hansen \& Dim, 2019; Innes \& Anderson, 2015). For example, Statistics Canada (2015) reports that Indigenous men are 7 times more likely to die from homicide than non-Indigenous men and 3 times as likely compared with Indigenous women.

Despite the magnitude of various forms of violence against Indigenous men, violence in the form of IPV against Indigenous men is scarcely reported or researched (Brownridge, 2010). Brownridge (2010), using Canada's General Social Survey conducted in 1999, is one of very few studies exploring IPV against Indigenous men. This study reports that Indigenous men living off reserve experience IPV at about 2.5 to 3.5 times the rate of victimization compared with their non-Indigenous counterparts, and further that the victimization tends to be more severe. Brownridge's analysis (2010) contradicts the more common narrative of intimate relationship dynamics that casts Indigenous men as the main abuser in gender-based violence. The propagation of the narrative that Indigenous men are solely the perpetrators of violence instead of survivors of violence conceals complex consequences of colonization and hinders the creation of urgently needed prevention strategies, interventions, and services targeted at Indigenous men (Innes \& Anderson, 2015). 


\section{Objectives of This Study}

We conducted qualitative research with primary care providers ${ }^{1}$ in rural medical clinics located adjacent to or in First Nations communities to document their understanding of First Nations clients who experience IPV. The objective was to explore how providers respond to clients who are experiencing IPV, with the intent to improve cultural safety in the primary health care setting. Initially our research focused on IPV experienced by Indigenous women (Rizkalla et al., 2020); however, many providers stressed that Indigenous men are also significantly impacted by IPV and pointed to significant gaps in services. This paper explores the providers' perceptions of IPV against Indigenous men and the related implications for primary care service development and future research needs for northern and rural communities.

\section{Methods}

\section{Study Design}

This study employed a qualitative, community-based participatory research (CBPR) approach with participating Indigenous communities in the Manitoulin District, a rural region in northeastern Ontario. Manitoulin has a population of about 13,000 residents. Of this population, approximately 5,260 people are Indigenous and there are seven First Nations communities (Statistics Canada, 2017). The interview data collection occurred at two First Nations health centres and in two neighbouring communities. The analysis used a grounded theory approach to allow exploration of emerging themes (Charmaz, 2014, 2017). The study was conducted over a two year period, and completed in 2019.

\section{Participants}

After the research was approved by First Nations community leadership, the research team invited health organizations in two First Nations communities and two rural Family Health Teams, and associated emergency departments (providing services in the surrounding towns and First Nations on Manitoulin Island) to participate in focus groups. Posters advertising the nature, relevance, and expected outcomes for the study were sent to the primary care managers by email. Eligible providers included individuals who (a) provided direct services to First Nations patients or clients, and (b) found IPV relevant to their practice. Providers in this study included regulated and nonregulated health care providers, such as physicians, registered nurses, nurse practitioners, physiotherapists, social workers, mental health workers, and various community health workers (refer to Table 1). Once interest in a focus group was confirmed, a date was picked to optimize attendance at each site.

To better understand emerging themes from data collection, nuances, and contradictory experiences between the providers, the researchers used theoretical sampling consistent with grounded theory (Charmaz, 2014, 2017). Therefore, two providers who were unavailable to attend the focus group were invited to a semistructured interview on an alternate date. The

${ }^{1}$ Hereafter referred to as "providers." 
corresponding author (MM), who has more than 20 years of experience co-creating qualitative research with First Nations, facilitated the focus groups and interviews with the primary author (KR).

\section{Data Collection}

Thirty-one health care providers participated over the course of four focus groups and two semistructured interviews. Two of the focus groups as well as both interviews were with members of Family Health Teams based in the rural clinics off reserve. The remaining two focus groups were with First Nations health organizations on reserve. The average duration of a focus group was 2 hours, and the interviews lasted approximately 1 hour. The participants provided written consent to participate and then shared their experiences about IPV as providers through facilitated discussion.

\section{Data Management and Analysis}

The grounded theory approach required that data be analyzed immediately after each session so that focus group questions could be adapted to explore emerging topics (Charmaz, 2014). The analysis was inductive, meaning that themes and categories were not predetermined but rather emerged from the data. First, the data were transcribed verbatim and then coded by researchers (KR, MM) using NVivo 12, a qualitative software program. To ensure the validity of emerging themes and categories, the data coding was independently performed by these researchers and then presented to co-researchers from communities and health organizations. Themes were compared and contrasted until consensus was reached by all researchers.

\section{Relationship}

Building on a 2-decade-long research relationship, the senior researcher was invited by a regional First Nations health organization to lead a research-priority-setting exercise in 2016. The intent of this collaboration was to develop a CBPR project on a prioritized health issue. IPV arose as an issue that primary care providers saw as widespread with serious health and mental health consequences, while at the same time underaddressed and lacking a coordinated service approach.

This finding gave rise to a strengths-based project on Indigenous perspectives on healthy relationships (Bennett et al., 2019). The participating First Nations approved the resulting research program on IPV by formal resolutions. The next phase was identified in discussions with community advisers and focused on a better understanding of service providers' needs on and off reserve, with the ultimate goal of strengthening their response to Indigenous women who experienced violence. The results of that study also revealed an important, albeit previously undeclared, concern addressed in the current paper, which was that of IPV against Indigenous men in heterosexual relationships as a hidden health issue.

This research project obtained ethics approval from Laurentian University Research Ethics Board (REB \#6009722) (Laurentian University, n.d.). It also underwent a culturally based 
ethics review from the Manitoulin Anishinaabek Research Review Committee (Noojmowin Teg Health Centre, n.d.).

\section{Results}

The characteristics of the 31 participating providers are shown in Table 1 . The providers represented two First Nations health centres (with predominantly Indigenous staff) as well as two health teams located off reserve (with predominantly non-Indigenous staff) who regularly provide services to the same First Nations communities.

\section{Table 1}

Participant Characteristics

\begin{tabular}{|c|c|c|c|c|c|c|c|}
\hline \multirow[t]{2}{*}{ Community } & \multicolumn{2}{|c|}{$\begin{array}{l}\text { Focus group } \\
\text { and interview } \\
\text { participants }\end{array}$} & \multirow[t]{2}{*}{ Physicians } & \multirow[t]{2}{*}{ Nurses } & \multirow[t]{2}{*}{$\begin{array}{l}\text { Community } \\
\text { health } \\
\text { workers }\end{array}$} & \multirow[t]{2}{*}{$\begin{array}{l}\text { Social workers, mental } \\
\text { health workers }\end{array}$} & \multirow[t]{2}{*}{$\begin{array}{l}\text { Other } \\
\text { primary } \\
\text { care }\end{array}$} \\
\hline & Men & Women & & & & & \\
\hline $\begin{array}{l}\text { Family Health } \\
\text { Team, } \\
\text { Community } 1\end{array}$ & 1 & 7 & 2 & 1 & & 2 & 3 \\
\hline $\begin{array}{l}\text { Family Health } \\
\text { Team, } \\
\text { Community } 2\end{array}$ & 1 & 6 & 4 & & 1 & 2 & \\
\hline $\begin{array}{l}\text { First Nations } \\
\text { health } \\
\text { organization, } \\
\text { Community } 3\end{array}$ & 1 & 9 & & & 8 & 1 & 1 \\
\hline $\begin{array}{l}\text { First Nations } \\
\text { health } \\
\text { organization, } \\
\text { Community } 4\end{array}$ & 0 & 6 & & 1 & 4 & & 1 \\
\hline TOTAL & 3 & 28 & 6 & 2 & 13 & 5 & 5 \\
\hline
\end{tabular}

Health providers shared their perceptions based on their clinical experiences with men who have been abused by women in intimate relationships. The themes that arose from the grounded theoretical analysis are as follows: (a) IPV against Indigenous men is a primary health care issue, (b) common disclosures include experiences of severe emotional and physical abuse, (c) men face barriers and potential harms when reporting IPV, and consequently, (d) there are significant cultural safety gaps for Indigenous men experiencing IPV. These providers also had suggestions for how to address IPV experienced by Indigenous men in a culturally safe way in the primary care setting.

\section{IPV Against Indigenous Men Is a Primary Health Care Issue}

The providers made it evident that men in the district of Manitoulin experience IPV and that this is increasingly disclosed in a clinical setting. 
I have had men say to me that they've been abused. $(\mathrm{C} 2, \mathrm{P} 6)^{1}$

Anecdotally, couldn't give you numbers, but I would have to say that certainly more men are presenting and talking about being victims themselves. $(\mathrm{C} 1, \mathrm{P} 8)$

Some providers believed physical IPV against men was a long-standing hidden issue, while others perceived a more recent shift of relationship dynamics between men and women, particularly with younger patients.

I think relationships that may be at one time primarily more controlling behaviour and those nonphysical forms of power and control exertion and manipulation and stuff like that has shifted into becoming more hands-on from women to men. $(\mathrm{C} 2, \mathrm{P} 7)$

Generally, those providers with more experience of addressing IPV in a clinical setting had more awareness of IPV against men as a health issue. Indigenous providers who lived in their communities had their knowledge of IPV mainly shaped by their knowledge of the community and believed there was very significant underreporting in the primary care setting.

\section{Common Disclosures Include Experiences of Severe Emotional and Physical Abuse}

Providers shared cases of IPV against their male clients that were disclosed in the primary care setting. The violence endured in the relationship in these cases was often severe and ranged from physical to emotional/psychological abuse.

I guess his girlfriend took a cast-iron frying pan and hit him over the head with it. So he had some challenges there ... they give you this backstory about this man, how he'd been abused. So I mean it happens with men, it tends to be a little bit more violent sometimes. $(\mathrm{C} 3, \mathrm{P} 9)$

Emotional abuse in the form of controlling First Nations men's interactions with others and with the partner was also discussed.

I have two [First Nations] men in my practice who have disclosed that they have been, well, what I would consider to be in abusive relationships. And in neither of those would I consider physical violence as the issue. It's more of a control issue, more of a "if you don't do what I want, I'm gonna walk out with the kids" issue. And he is very distraught: "I'm not allowed to have any friends, I'm not allowed to do this, I'm not allowed to do

\footnotetext{
${ }^{1}$ Abbreviation for community and participant identification.
} 
that, because if I do, she'll walk with the kids." ... So I believe that it's quite possible for men to be abused. (C2, P1)

One provider explained that the emotional abuse can directly impact on and worsen the physical health of their male patients and explained how abusive relationships are a major barrier in the management of chronic illnesses.

I can tell when things are going well, because [the men's] blood work improves, and so those kinds of things. And how they've walked away from the relationship only to go back because that's the only way they're gonna have access to the kids, you know, that kind of stuff. (C2, P1)

Clearly, the effect of physical, mental, and emotional abuse can be further amplified by exacerbating men's preexisting health issues, particularly chronic health and mental health issues. At times, men decide to accept the abuse in order to maintain relationships with their children, despite the negative effect on their physical and mental health.

\section{Men Face Barriers and Potential Harms When Reporting IPV}

Although more men are coming forward and disclosing IPV, some providers believe that there is even more significant underreporting in the clinical setting when compared to reporting of IPV against women. One provider estimated the proportion of men to women who are being abused based on their experience in their practice.

I think men are less likely to talk about it [...] I just think it's not really reported. Just like [the other provider] said, it's probably half [of all abuse cases are perpetrated against men]. (C3, P6)

The providers explained that there are First Nations men in their practice who are being abused and that serious social barriers often hinder disclosure. In many cases, men seem to have a difficult time expressing that they have been victimized, possibly because of the associated stigma or shame to their masculinity from being abused by a woman. One provider recounted a time an Indigenous man disclosed he was being abused by an intimate partner where stigma and shame were a factor.

I've seen at least one man in the emergency department who was pushed and shoved by his intimate partner. He was an Indigenous man. He felt ashamed and had difficulty even reporting it because it would tell the people that your woman is shoving you around. It's laughable in most cultures, right? $(\mathrm{C} 1, \mathrm{P} 1)$

Some providers admitted to hesitating to believe accusations coming from men, particularly when there were conflicting statements given from each side of the relationship. 
It affects men too. I have had men say to me that they've been abused. I think it's often around the legal thing, so when a couple have an argument, they both reach for the phone, and they both state that the other one was violent. ... So you have "he said, she said" [...] I'm never quite sure when men reveal to me that they've been hit or they've been hurt. (C2, P6)

Furthermore, men report to providers that they have a difficult time when police are called to intervene; they are concerned that they may not be believed, since stereotypically women are thought of as victims, not perpetrators.

There's this unfortunate man [who has been abused] who has nowhere to go, and where do you send this man? And he says, "oh yeah, there's a couple of houses here for men, they're called prisons." (C1, $\mathrm{P} 1)$

The narratives underscore several underlying difficulties related to understanding IPV directed against First Nations men and responding to it in the primary care setting. First, men perceive social harms that prevent them from disclosing IPV, which leads to underreporting. Second, violence may occur in a bidirectional manner and it can be difficult to determine to what extent a man is victimized. Third, providers may be unconsciously biased against believing a man can be victimized at all. This bias has serious consequences when, in response to disclosure, IPV against a man is misinterpreted by law enforcement as violence perpetrated by him against a woman. Therefore, First Nations men may feel unsafe to disclose IPV to primary care providers if they believe that law enforcement might become involved, especially if they already had experiences of discrimination and racial disparities in the justice system.

\section{There Are Significant Cultural Safety Gaps for Indigenous Men Experiencing IPV}

Services such as IPV counselling, support groups, and shelters tend to be mostly geared toward women. More culturally based services for women are certainly needed, but there are almost none for First Nations men in this area.

You can send women to [the shelter] ... and they get counselling and support, but with men there's nothing! There's nothing! (C1, P1)

Culturally safe services to intervene in crisis situations or to provide follow-up and aftercare services for First Nations men who experience IPV have not been developed.

\section{Limitations}

This study represents the perspectives of providers in Family Health Teams and in First Nations health centres in one region of Northern Ontario, and the results are not necessarily generalizable to all Indigenous communities in Canada. However, given the emerging research 
findings of the high rates of violence against Indigenous men, and the similar findings at the four sites in this study, it is likely that the response to IPV in the primary care setting requires development elsewhere in Canada. A broader discussion, involving more regions and cultural groups on policy implications of IPV experienced by Indigenous men, based on their own perspectives, is needed.

\section{Discussion}

Our findings challenge the common narrative that Indigenous men are mainly perpetrators rather than also frequent survivors of IPV. Providers in this study were most often responding to male clients who disclosed experiencing severe forms of physical and emotional abuse. Observed health consequences went beyond acute injuries and contributed to anxiety, depression, worsening of clinical lab values, and poor management of chronic illnesses. Thus, this study focused on Indigenous men supports the finding, noted in research on men in general, of adverse physical and psychological consequences of IPV, including physical injury requiring medical attention, disempowerment, shame, and depression (Follingstad et al., 1991; Hines \& Malley-Morrison, 2001; Statistics Canada, 1998). Clearly, IPV is a significant primary care issue for Indigenous men and requires more focus in terms of research and services.

While rates of male disclosure of IPV seem to be increasing, many providers speculated that Indigenous men still have great difficulty disclosing IPV. Therefore, it may be that only severe cases were disclosed, while financial or spiritual abuse or less explicitly violent forms of physical and mental abuse were perhaps not reported or missed. Providers require information and training on how to initiate conversations on IPV with Indigenous men in a culturally safe manner in the health services setting. However, follow-up services for men are mostly lacking, and advocacy is needed to create strengths-based and culturally informed support systems.

This study demonstrated that many providers have observed adverse outcomes of IPV experienced by First Nations men; however, some providers still struggle to accept that men can experience violence perpetrated by their female partners. Underreporting is therefore likely due to (a) men experiencing stigma to Indigenous masculinity when reporting IPV, as well as (b) some providers being conflicted about the veracity of these disclosures. This reality makes disclosure of experienced IPV socially risky for Indigenous men. Providers require training on men's experiences of IPV as well as on unconscious racial and gender biases related to IPV.

Furthermore, Innes (2015, p. 55) argues that "to address violence against Indigenous women successfully, a strategy should also address Indigenous men both as victimizers and as victims," which underscores the importance of addressing this overlooked issue. For example, there is a need for cultural and clinical programs and services to teach the skills to engage in healthy relationships for those men who are involved in bidirectional IPV. An Indigenous wellness framework, such as the First Nations Mental Wellness Continuum Framework, should be consulted to develop service coordination and a culturally safe contiuum of services to foster healthy relationships (Health Canada, 2015; Thomas \& Green, 2007). 
The perception of many providers that there is significant exposure of Indigenous men to IPV is congruent with emerging research documenting the high risk of violence experienced by Indigenous men (Brownridge, 2010; Innes \& Anderson, 2015). Our research also shows that IPV against Indigenous men and a response to this phenomenon cannot be separated from the harmful ongoing consequences of colonialism. Innes \& Anderson (2015) argue that there is "little activism or political will to address Indigenous men's issues, and as a result there are very few policies or social programs designed for Indigenous men" (p. 3). This is also true with respect to IPV against Indigenous men. Our findings are therefore particularly significant because providers can play important roles in improving abused individuals' quality of life, including acting as advocates for social and policy change and helping to reduce gendered racial biases in the health care system (Black, 2011; Kalra et al., 2017).

To begin to set a direction to address IPV against Indigenous men, we provide recommendations, based on our findings, for the development of a culturally safe response in primary health care for Indigenous men who experience IPV.

\section{Recommendations}

1. Develop primary care student education and professional training on Indigenous men's and women's experiences of IPV, as well as related unconscious bias and gendered racism, with the goal of making the clinical setting a more culturally safe space to disclose IPV.

2. Encourage providers to use their roles as health advocates and Indigenous allies to support health and social policy improvements to reduce IPV and its negative effects on Indigenous people, families, and communities.

3. Develop primary and secondary prevention strategies focused on educating men and women on healthy relationship skills and traditional gender role teachings. IPV prevention focused on the primary care setting should include posters in hospitals and clinics acknowledging the many forms of IPV, promoting culturally based teachings on healthy relationships, and stressing that both men and women experience IPV.

4. Increase community awareness and create safe spaces for IPV prevention activities. In these spaces, individuals may learn about the long-term consequences of experiencing childhood abuse, which might normalize the experience of violence as perpetrators and victims for men and women in their adult relationships. Focusing on cultural strengths related to relationships, such as teaching about healthy relationships from an Indigenous cultural perspective, can be an important strategy to de-normalize IPV.

5. Identify a continuum of services and address service gaps. This may include identifying culturally safe screening approaches, and developing culturally safe, culturally based, and trauma-informed services for Indigenous men who experience IPV.

6. Develop culturally based programs for perpetrators of IPV.

7. Expand research on men's experiences of IPV, including the experience of Indigenous men with other gender identities and sexual orientations. 
8. Expand research on protective and risk factors associated with Indigenous men's involvement in violent relationships as well as cultural strengths that promote healing from IPV.

\section{Conclusion}

The results of this study suggest that primary care providers are increasingly aware of the negative effects of IPV on the health and well-being of Indigenous men, yet primary care providers have little training and few resources to provide a culturally safe response. To ameliorate the impact of IPV on Indigenous men, collaborative action is required by researchers, clinicians, educators, health care administrators, and policymakers. More comprehensive research is needed in Indigenous communities to document the types and rates of IPV perpetrated against Indigenous men, their impact on the health and well-being of Indigenous men, and the corresponding cultural, health, and social service needs. In response, culturally based and trauma-informed services for healing from the consequences of IPV need to be developed, based on Indigenous frameworks for wellness that build on cultural strengths and the community as the ultimate resource for healing.

\section{References}

Amnesty International. (2004). Stolen sisters: A human rights response to discrimination and violence against Indigenous women in Canada. https://www.amnesty.ca/sites/amnesty/files/amr200032004enstolensisters.pdf

Andersson, N., \& Nahwegahbow, A. (2010). Family violence and the need for prevention research in First Nations, Inuit, and Métis Communities. Pimatisiwin: A Journal of Aboriginal and Indigenous Community Health, 8(2), 9-33. http://www.pimatisiwin.com/online/wpcontent/uploads/2010/09/04AnderssonNawegahbow.pdf

Bartlett, J. G., Iwasaki, Y., Gottlieb, B., Hall, D., \& Mannell, R. (2007). Framework for Aboriginal-guided decolonizing research involving Metis and First Nations persons with diabetes. Social Science \& Medicine, 65(11), 2371-2382. https://doi.org/10.1016/j.socscimed.2007.06.011

Bennett, B., Maar, M., Manitowabi, D., Moeke-Pickering, T., Trudeau-Peltier, D., \& Trudeau, S. (2019). The Gaataa'aabing visual research method: A culturally safe Anishinaabek transformation of photovoice. International Journal of Qualitative Methods, 18, 1-12. https://doi.org/10.1177/1609406919851635

Benoit, C., Shumka, L., Phillips, R., Kennedy, M. C., \& Belle-Isle, L. (2015, December). Issue brief: Sexual violence against women in Canada. Federal-Provincial-Territorial Senior Officials for the Status of Women. Retrieved from Status of Women Canada website: https://cfc-swc.gc.ca/svawc-vcsfc/issue-brief-en.pdf

Black, M. C. (2011). Intimate partner violence and adverse health consequences: Implications for clinicians. American Journal of Lifestyle Medicine, 5(5), 428-439. https://doi.org/10.1177/1559827611410265 
Brownridge, D. A. (2003). Male partner violence against Aboriginal women in Canada: An empirical analysis. Journal of Interpersonal Violence, 18(1), 65-83. https://doi.org/10.1177/0886260502238541

Brownridge, D. A. (2010). Intimate partner violence against Aboriginal men in Canada. Australian \& New Zealand Journal of Criminology, 43(2), 223-237. https://doi.org/10.1375/acri.43.2.223

Centers for Disease Control and Prevention. (2018). Intimate partner violence. https://www.cdc.gov/violenceprevention/intimatepartnerviolence/index.html

Charmaz, K. (2014). Constructing grounded theory (2nd ed.). SAGE Publications.

Charmaz, K. (2017). The power of constructivist grounded theory for critical inquiry. Qualitative Inquiry, 23(1), 34-45. https://doi.org/10.1177/1077800416657105

Desmarais, S. L., Reeves, K. A., Nicholls, T. L., Telford, R. P., \& Fiebert, M. S. (2012a). Prevalence of physical violence in intimate relationships, part 1: Rates of male and female victimization. Partner Abuse, 3(2), 140-169. https://doi.org/10.1891/19466560.3.2.140

Desmarais, S. L., Reeves, K. A., Nicholls, T. L., Telford, R. P., \& Fiebert, M. S. (2012b). Prevalence of physical violence in intimate relationships, part 2: Rates of male and female perpetration. Partner Abuse, 3(2), 170-198. https://doi.org/10.1891/19466560.3.2.170

Fiebert, M. S. (2014). References examining assaults by women on their spouses or male partners: An updated annotated bibliography. Sexuality \& Culture, 18, 405-467. https://doi.org/10.1007/s12119-013-9194-1

Follingstad, D. R., Wright, S., Lloyd, S., \& Sebastian, J. A. (1991). Sex differences in motivations and effects in dating violence. Family Relations, 40(1), 51-57. https://doi.org/10.2307/585658

Hansen, J. G., \& Dim, E. E. (2019). Canada's missing and murdered Indigenous people and the imperative for a more inclusive perspective. International Indigenous Policy Journal, 10(1), Article 2. https://doi.org/10.18584/iipj.2019.10.1.2

Health Canada. (2015). First Nations Mental Wellness Continuum Framework. Retrieved from Thunderbird Partnership Foundation website: https://thunderbirdpf.org/wpcontent/uploads/2015/01/24-14-1273-FN-Mental-Wellness-Framework-EN05_low.pdf

Hines, D. A., \& Malley-Morrison, K. (2001). Psychological effects of partner abuse against men: A neglected research area. Psychology of Men \& Masculinity, 2(2), 75-85. https://doi.org/10.1037/1524-9220.2.2.75

Indigenous and Northern Affairs Canada. (2001, December). Aboriginal women: A profile from the 1996 census (2nd ed.). https://www.aadncaandc.gc.ca/eng/1100100016869/1100100016871

Innes, R. A. (2015). Moose on the loose: Indigenous men, violence, and the colonial excuse. Aboriginal Policy Studies, 4(1), 46-56. https://doi.org/10.5663/aps.v4i1.24193

Innes, R. A., \& Anderson, K. (2015). Introduction: Who's walking with our brothers? In R. A. 
Innes \& K. Anderson (Eds.), Indigenous men and masculinities: Legacies, identities, regeneration (pp. 12-43). University of Manitoba Press.

Kalra, N., Di Tanna, G. L., \& García-Moreno, C. (2017). Training healthcare providers to respond to intimate partner violence against women. Cochrane Database of Systematic Reviews, Issue 2, Article CD012423. https://doi.org/10.1002/14651858.CD012423

Klingspohn, D. M. (2018). The importance of culture in addressing domestic violence for First Nation's women. Frontiers in Psychology, 9, Article 872.

https://doi.org/10.3389/fpsyg.2018.00872

Laurentian University. (n.d.). Ethics. https://laurentian.ca/research/ethics

Mt. Pleasant, J. (2016). Violence against Indigenous males in Canada with a focus on missing and murdered Indigenous men. Social Justice and Community Engagement, 11. https://scholars.wlu.ca/brantford_sjce/11

National Inquiry into Missing and Murdered Indigenous Women and Girls. (2019). Reclaiming power and place: The final report of the National Inquiry into Missing and Murdered Indigenous Women and Girls. https://www.mmiwg-ffada.ca/final-report/

Noojmowin Teg Health Centre. (n.d.). Manitoulin Anishinaabek Research Review Committee. https://www.noojmowin-teg.ca/programs-services/manitoulin-anishinabek-researchreview-committee

Ontario Native Women's Association. (1989). Breaking free: A proposal for change to Aboriginal family violence. https://www.onwa.ca/reports

Rizkalla, K., Maar, M., Pilon, R., McGregor, L., \& Reade, M. (2020). Improving the response of primary care providers to rural First Nation women who experience intimate partner violence: A qualitative study. BMC Women's Health, 20, Article 209. https://doi.org/10.1186/s12905-020-01053-y

Romans, S., Forte, T., Cohen, M. M., Du Mont, J., \& Hyman, I. (2007). Who is most at risk for intimate partner violence? A Canadian population-based study. Journal of Interpersonal Violence, 22(12), 1495-1514. https://doi.org/10.1177/0886260507306566

Statistics Canada. (1998, January 13). 1996 Census: Aboriginal data. The Daily. https://www150.statcan.gc.ca/n1/daily-quotidien/980113/dq980113-eng.htm

Statistics Canada. (2015). Homicide in Canada, 2014. https://www150.statcan.gc.ca/n1/pub/85002-x/2015001/article/14244-eng.htm\#a13

Statistics Canada. (2017, November 29). Manitoulin, District [Census division], Ontario and Ontario [Province] [Table]. Census Profile, 2016 Census. Catalogue No. 98-316X2016001.

Thomas, R., \& Green, J. (2007). A way of life: Indigenous perspectives on anti oppressive living. First Peoples Child \& Family Review, 3(1), 91-104. https://fpcfr.com/index.php/FPCFR/article/view/27

World Health Organization. (2012). Understanding and addressing violence against women: Intimate partner violence. http://apps.who.int/iris/bitstream/10665/77432/1/WHO_RHR_12.36_eng.pdf 